\title{
Perceptivas que posibilitan Los Cursos Virtuales en Moodle en Programas de Pregrado de la Universidad de Pamplona
}

\author{
Perceptions That Possible Virtual Courses in Moodle In Undergraduate Programs Of The \\ University Of Pamplona
}

\author{
Rolando Quintero Pérez ${ }^{1}$ \\ https://orcid.org/0000-0003.2844-5514 \\ Olga Lorena González Maldonado ${ }^{2}$ \\ https://orcid.org/0000-0001-6531-3372 \\ Kleeder José. Bracho Pérez ${ }^{3}$ \\ https://orcid.org/0000-0003-3644-0561 \\ Universidad de Pamplona, Colombia
}

Recibido:25-08-2020

Aceptado: 21-12-2020

\section{Cita Recomendada}

Quintero, R. González, O.L., \& Bracho, K. (2020). Perceptivas que posibilitan los cursos virtuales en Moodle en programas de pregrado de la Universidad de Pamplona. Hamut' ay, 7 (3), 60-74

http://dx.doi.org/10.21503/hamu.v7i3.2193

\section{Resumen}

El estudio se realizó con el propósito de evaluar las características perceptivas que posibilitan los cursos de formación Ciudadana y Cultura de la Paz y Educación Ambiental en el marco de las asignaturas virtuales (Moodle) en los programas de pregrado de la Universidad de Pamplona, Sede Villa del Rosario, Norte de Santander, Colombia, desde la perspectiva de la teoría de la Gestalt. La metodología se basó en la filosofía post positivista bajo un enfoque cualitativo, con método descriptivo y de corte transversal. Los informantes claves estuvieron representados por siete (7) estudiantes seleccionados aleatoriamente, matriculados para el periodo 2020-1. Se aplicó una encuesta con preguntas abiertas que buscaban recabar la mayor cantidad de información necesaria que sirviera de insumo para la validación de la estructura gestáltica de los diferentes cursos virtuales de la Universidad de Pamplona. La información recolectada se trabajó mediante las fases de la investigación en tres grandes momentos: observación, recolección de información y análisis e interpretación. El estudio permitió concluir que la aplicación de una fundamentación teórica como la de Gestalt, mejoraría significativamente la percepción del estudiante en los cursos virtuales, permitiendo contar con estándares audiovisuales idóneos y superar la carencia de habilidades en la ejecución de procesos académicos fundamentados en TIC, que dificultan el adecuado funcionamiento dentro de la ejecución de las actividades en asignaturas de tipo virtual.

Palabras clave: perspectiva, Moodle, cursos virtuales, programas, Gestalt.

\footnotetext{
1. Magister Gestión de Proyectos Informáticos, Universidad de Pamplona. E-mail:rolando_quintero@hotmail.com

2. Magister en Educación, Docente, Universidad de Pamplona. E-mail: olgalorena.gonzalez@gmail.com

3. Doctor en Ciencias de la Educación, Docente, Universidad de Pamplona. E-mail: kleeder8@hotmail.com
} 


\begin{abstract}
The study was carried out with the purpose of evaluating the perceptual characteristics that make possible the Citizen and Culture of Peace and Environmental Education training courses within the framework of virtual subjects (Moodle) in the undergraduate programs of the University of Pamplona, Villa Sede del Rosario, Norte de Santander Colombia, from the perspective of Gestalt theory. The methodology was based on the post-positivist philosophy under a qualitative approach, with a descriptive and cross-sectional method. Key informants were represented by seven (7) randomly selected students enrolled for the 2020-1 period. A survey was applied with open questions that sought to collect the greatest amount of information necessary to serve as input for the validation of the Gestalt structure of the different virtual courses at the University of Pamplona. The information collected was worked through the phases of the investigation in three main moments: observation, information collection and analysis and interpretation. The study allowed to conclude that the application of a theoretical foundation such as Gestalt, would significantly improve the student's perception in virtual courses, allowing them to have suitable audiovisual standards and overcome the lack of skills in the execution of academic processes based on ICT, which hinder the proper functioning within the execution of activities in virtual subject
\end{abstract}

Key words: perspective, Moodle, virtual courses, programs, Gestalt.

\section{Introducción}

El proceso de enseñanza - aprendizaje hace referencia a todos aquellos factores determinantes que llevan al estudiante a escuchar detenidamente al docente, a presentar un mayor interés para interactuar con este con el afán de aclarar las dudas que se le presenten, a participar activa y dinámicamente de la clase, a realizar y ejecutar las diferentes actividades propuestas, a estudiar conscientemente con las técnicas adecuadas, en una palabra, es la fuerza que lleva al individuo a investigar, experimentar y aprender de manera constructiva y significativa. Al respecto del Moral y Martínez (2012) afirman que:

El profesor universitario ha de añadir, por tanto, a sus funciones tradicionales como docente, tutor e investigador, una cuarta función como experto en Tecnologías de la Información y Comunicación (TIC) que le capacite no solo para utilizar didácticamente las herramientas y aplicaciones procedentes de la web 2.0 convirtiéndolas en un recurso más dentro del aula, sino también para desempeñar su propia labor docente inmerso en los nuevos escenarios virtuales (p.38).

La percepción del estudiante dentro del proceso de enseñanza - aprendizaje en ambientes virtuales es fundamental para lograr los objetivos, incluso es un factor determinante para la consecución de nuevo conocimiento y las habilidades necesarias para su aplicación en solución de si- tuaciones de la vida cotidiana. Por lo anterior, la percepción dentro del aprendizaje virtual incrementa el esfuerzo, la persistencia y la iniciativa para mejorar el procesamiento cognitivo que lleva a la optimización del desempeño general del estudiante, teniendo como premisa de acción el "yo puedo hacerlo" el cual se refiere a los conocimientos, capacidades, estrategias, y destrezas necesarias que aunadas a la disposición y la intención permiten conseguir dichos objetivos Naula, (2017).

El avance de las TIC posibilita al individuo estudiar en cualquier parte rompiendo las barreras de espacio - tiempo, en las cuales se enmarca la educación tradicional del siglo XX. La educación virtual es el componente donde se interrelacionan sinérgicamente docente, estudiante, tecnología y medio ambiente. Así mismo, una asignatura virtual permite ejecutar en línea los contenidos de una materia mediante la utilización de herramientas tecnológicas como la computadora, internet y una plataforma de aprendizaje, Gregori y Garganté (2005, p.9) afirman "El estudiante no sólo debe conocer cómo navegar por un sitio con materiales hipermedia de contenido: además debe saber cómo utilizarlos para potenciar su aprendizaje".

Los cursos en línea en la Universidad de Pamplona mediante la plataforma Moodle se han convertido en un constante desafío desde su implantación en el año 2015 que ha revolucionado el 
paradigma tradicional de educación estableciendo un proceso comunicativo entendido como "la interacción dotada de sentido entre un ser humano y su entorno. El ser humano es un sistema abierto y un sistema complejo y, en relación a la información, constituye un sistema de comunicación retroalimentado" Colle, (2002, p.12). Así mismo, dicha evolución y la necesidad de enfocar el desarrollo en la calidad en los procesos educativos han aumentado los índices de deserción, pérdida y/o cancelación de asignaturas virtuales debido a la deficiente estructuración de los contenidos virtuales, lo cual hace imperativo que se realice una validación del proceso tanto en fases previas como posteriores al desarrollo de las mismas.

Muchas instituciones de educación superior creen que con el montaje de una plataforma que soporte un ambiente virtual y la estructuración de unos contenidos programáticos (en la mayoría de los casos, preestablecidos para la presencialidad) ya pueden brindar un servicio de virtualidad académica para diferentes asignaturas y programas, desconociendo en gran medida que dentro las diferencias marcadas que existen entre estas dos metodologías, y obviando fundamentos o posturas teóricas de buenas prácticas que se encuentran en teorías como la de Gestalt, que pueden mejorar a través de los principios de la percepción como contraste de figura fondo, la sencillez, la proximidad, la similaridad y cierre, el aprendizaje significativo de los estudiantes, y determinar de manera directa la incidencia e impacto en la educación teniendo en cuenta las necesidades del entorno, de los estudiantes y los docente del siglo XXI Pérez, (2007).

Por lo mencionado anteriormente, se presenta en este estudio un trabajo investigativo apoyado en las leyes de percepción de la teoría de Gestalt que permita validar la idoneidad en la construcción de los cursos virtuales para materias como Educación Ambiental, Formación Ciudadana y Cultura de la Paz de la Sede Villa del Rosario de la Universidad de Pamplona, revisando de manera directa la estructura de las mismas con el fin de facilitar al estudiante la ejecución de los contenidos de dichas asignaturas. Con la finalidad de concebir mejoras en los procesos de aprendizaje de los estudiantes que cursan asignaturas virtuales dentro de la Universidad de Pamplona. Marrero y Pérez (2014, p. 55), afirman que "se hace necesaria la formación de competencias que busquen la integralidad del estudiante universitario mediante la conjunción de conocimientos, aptitudes y actitudes, que le permitan desenvolverse en la solución de problemas". En tal sentido, desde el punto de vista educativo, toda institución debe estar prolija a atender todos aquellos cambios diferenciales que en determinado momento impactan el desarrollo de las actividades académicas con el fin de afrontar y adaptar los procesos a dichos cambios, especialmente los tecnológicos. Una de las principales incidencias hoy en la educación, son la aplicación y apropiación de las TIC, ya que en el campo educativo abre un abanico de posibilidades didácticas que permiten establecer nuevas modalidades de estudio en la educación virtual, la educación a distancia y presencial pero apoyada hoy por hoy en la virtualidad. Por lo anterior, la excelencia se logra aprovechando "el tiempo, disciplinando las actividades, formando hábitos, cumpliendo compromisos, realizando esfuerzos, luchando ante las dificultades, pensando, actuando, sintiendo con base en valores positivos y cultivando cualidades". Quintero, (2003, p.61).

Por otra parte, en referencia a la educación virtual, el docente deja de ser un transmisor de conocimiento a convertirse en un mediador para la construcción del mismo, en otras palabras, "se debe planificar previamente el proceso de aprendizaje de forma más evidente, si es posible, que en el presencial" Duart y Sangrá, (2000, p. 8); por otra parte, el estudiante deja de ser un simple acumulador de información para convertirse en una persona que sabe qué hacer con la información. Todo este proceso de transformación educativa influenciada por el creciente avance tecnológico hace que los roles que intervienen dentro del proceso cambien de estructura y se enfoquen en otras perspectivas mejorando indudablemente la motivación cognitiva del estudiante.

Del mismo modo, el estudio se convierte en una oportunidad para indagar y conocer aspectos 
teóricos y prácticos relacionados con diferentes teorías, especialmente, la teoría de Gestalt y su importancia en el proceso constructivo de ambientes virtuales de aprendizaje, lo cual permea el proceso de aprendizaje del estudiante enmarcándolo dentro de un contexto educativo virtual, encontrando a su vez beneficios para el desarrollo integral del individuo, desde la garantía de una educación de calidad. Por lo anterior, "la educación sería el medio por el cual los sujetos adquieren las competencias necesarias y pertinentes para el escenario global" Castro, (2007, p. 165).

La validación dentro de un proceso informático se puede definir como la revisión al que se somete un programa para comprobar que cumple con ciertas especificaciones. Partiendo de este punto, dentro del proceso de enseñanza virtual en la Universidad de Pamplona se ha visto reiteradamente la cancelación y pérdida de las asignaturas virtuales por parte de los estudiantes, lo que conlleva a realizar una validación de la estructura desarrollada dentro de la plataforma Moodle para las mismas, teniendo en cuenta los principios y elementos de la Teoría de la Gestalt como base evaluativa, permitiendo así definir si dicha estructura incide al momento de realizar el proceso educativo virtual y está conllevando a la cancelación o pérdida de la asignatura matriculada.

\section{Teoría de Gestalt}

El término Gestalt tuvo su origen en Alemania $\mathrm{y}$ fue introducido a principios del siglo XX por Christian Von Ehrenfels definiéndose como: forma, figura, configuración, estructura y/o creación. En otras palabras, la Gestalt puede definirse como "el todo es siempre más que la suma de sus partes" refiriendo a las experiencias de cada persona en cuanto a la autorrealización y la búsqueda de decisiones acertadas, tendiendo a desarrollar el ser humano de forma libre y autónoma. La Gestalt no solo es la suma de doctrinas, teorías y enfoques mencionados anteriormente como partes de un todo, sino la integración creativa a un nuevo plan global, el cual es enmarcado dentro del Enfoque Gestáltico. Kofkka (1922, p.1), uno de sus fundadores dice que, si bien es cierto que la teoría de la Gestalt nace de la investigación psicológica, ésta debe ser entendida "más que una mera teoría de la percepción: incluso más que una mera teoría psicológica”. La Gestalt presume un cambio esencial en las formas de pensar, la metodología y epistemología de la ciencia tal como señala Martín y de la Rosa (2011, p.19) "la Gestalt surge de las teorías visuales y auditivas en una época en que los sentimientos, las emociones y cualquier otro contenido que procediera del interior de la persona y que expresara su personalidad más profunda, no eran tomados en cuenta".

Tabla 1. Principales autores que intervinieron en la creación y consolidación de La Teoría de Gestalt

\begin{tabular}{|c|c|c|}
\hline Autores & Teoría & Aporte \\
\hline $\begin{array}{c}\text { Max } \\
\text { Wertheimer }\end{array}$ & $\begin{array}{l}\text { Según Antón (2011) "La teoría } \\
\text { fue concebida por Max } \\
\text { Wertheimer (1880-1943) y se } \\
\text { desarrolla en Alemania a partir } \\
\text { de 1924. Este psicólogo alemán } \\
\text { sostenía que la conciencia debe } \\
\text { ser analizada como una } \\
\text { totalidad organizada. Los } \\
\text { pensamientos son percepciones } \\
\text { significativas y no un simple } \\
\text { conjunto asociado de imágenes } \\
0 \text { de eslabones estimulo- } \\
\text { respuesta (E-R)". }\end{array}$ & $\begin{array}{l}\text { - Investigó sobre la percepción de estructuras } \\
\text { ambiguas y complejas. } \\
\text { - Generó el fenómeno PHI el cual consiste en } \\
\text { percibir una ilusión de movimiento } \\
\text { continuo, en donde hay una sucesión de } \\
\text { imágenes a través de un taquistoscopio. }\end{array}$ \\
\hline $\begin{array}{l}\text { Wolfgang } \\
\text { Köhler }\end{array}$ & $\begin{array}{l}\text { Participó en el desarrollo de la } \\
\text { Teoría de Gestalt, interesándose } \\
\text { en las investigaciones sobre la } \\
\text { inteligencia animal y sobre las } \\
\text { formas físicas. }\end{array}$ & $\begin{array}{l}\text { Aportó a esta escuela el concepto de aprendizaje } \\
\text { por Insight. Es decir, el individuo llega } \\
\text { súbitamente a la solución mediante una } \\
\text { reorganización del campo perceptivo. }\end{array}$ \\
\hline Kurt Koffka & $\begin{array}{l}\text { Participio junto a Köhler, en los } \\
\text { trabajos sobre percepción } \\
\text { llevados a cabo por Wertheimer } \\
\text { (1912), sobre la Teoría de la } \\
\text { Forma o de la Estructura, } \\
\text { asumiendo la percepción como } \\
\text { la capacidad de ver totalidades } \\
\text { estructuradas y no elementos } \\
\text { aislados. }\end{array}$ & $\begin{array}{l}\text { - La percepción es un todo conformado por } \\
\text { sensaciones, asociación y atención. } \\
\text { - La sensación es todo aquello que existe y está } \\
\text { ligada completamente al estímulo. } \\
\text { - Cuando un elemento es convertido } \\
\text { sensación, el sujeto puede experimentarlo en } \\
\text { forma de imagen. } \\
\text { - La asociación nos permite saber por qué un } \\
\text { - elemento causa la aparición de otro. } \\
\text { - La atención influye en la estructura y el curso } \\
\text { de los procesos conscientes del individuo. }\end{array}$ \\
\hline Kurt Lewin & $\begin{array}{l}\text { Se le considera el padre de la } \\
\text { Psicología Social moderna e } \\
\text { hizo parte activa en el desarrollo } \\
\text { de la Psicología de la Gestalt. }\end{array}$ & $\begin{array}{l}\text { - Teoría del Campo: Las variaciones } \\
\text { individuales del comportamiento humanoen } \\
\text { relación a la norma son condicionadas por la } \\
\text { tensión entre las percepciones del individuo } \\
\text { y el contexto psicológico en el que se } \\
\text { encuentra. } \\
\text { - Teoría Topológica de la personalidad: Las } \\
\text { personas se encuentran dentro de un campo } \\
\text { psicológico de fuerzas que fijan la conducta } \\
\text { del individuo. } \\
\text { - El concepto de espacio vital: se refiere a la } \\
\text { forma como cada individuo percibe el } \\
\text { mundo que le rodea. De esta manera sepuede } \\
\text { decir que posee una parte subjetiva, pero, } \\
\text { además tiene una parte objetiva que son las } \\
\text { condiciones ambientales físicas y sociales, }\end{array}$ \\
\hline
\end{tabular}


que limitan el campo psicológico.

- Las tensiones se dan por los conflictos internos y las frustraciones del individuo al no lograr los objetivos que actúan como fuerzas motivadoras.

Fuente: Elaboración Propia (2020).

\section{Percepción}

En consideración a la percepción esta consiste en un intento por agrupar la información circundante dentro de las unidades simples que le permiten a la conciencia obtener noción de objeto y con ello mejorar su capacidad abstracta. Oviedo, (2004), en tal sentido, la percepción está definida como la capacidad de los sujetos para obtener información del entorno a partir de los estímulos que producen los sentidos, lo cual permite al individuo interaccionar con el ambiente que lo rodea.

Por otra parte, Carterette y Friedman, (1982), consideraron la percepción como una etapa subjetiva, a través del cual se realiza una abstracción del mundo externo o de hechos relevantes, es decir un proceso inicial de la acción mental y no un procedente cerebral de estados sensoriales y Vargas, (2008) considera que la percepción del sujeto será una línea única moviéndose desde la posición de la primera a la de la segunda línea. (p.3)

Del mismo modo, la Gestalt es entendida como una tendencia al orden mental; inicialmente la percepción establece la entrada de información, garantizando que los datos tomados del ambiente posibiliten la formación de abstracciones, (juicios, categorías, conceptos, entre otros) Gilberto, (2004).

Tabla 4. Percepciòn y Educación Virtual

\begin{tabular}{|c|c|}
\hline \multicolumn{2}{|r|}{ Características de la percepción } \\
\hline Inferencial & $\begin{array}{l}\text { Como primer proceso cognoscitivo toma la información del medio para } \\
\text { realizar una interpretación de una imagen o idea a partir de la } \\
\text { decodificación de estímulos sensoriales. }\end{array}$ \\
\hline Constructiva & $\begin{array}{l}\text { Se encarga de construir una idea basada en datos nuevos y preexistentes } \\
\text { en la memoria del individuo. }\end{array}$ \\
\hline $\begin{array}{l}\text { Percepción y sensación } \\
\text { son diferentes. }\end{array}$ & $\begin{array}{l}\text { La percepción interpreta una sensación, que aporta significado y orden } \\
\text { en el individuo. } \\
\text { La sensación vive una experiencia a partir de un estímulo. }\end{array}$ \\
\hline Depende de los sentidos & $\begin{array}{l}\text { Visual para la percepción de imágenes. } \\
\text { Auditiva para la percepción de sonidos. } \\
\text { Olfativa para la percepción de aromas. } \\
\text { Gustativa para la percepción de sabores. } \\
\text { Táctil para la percepción de mediante contacto físico. }\end{array}$ \\
\hline La atención & $\begin{array}{l}\text { Es el filtro que permite seleccionar los estímulos importantes y/o } \\
\text { significativos que percibe el sujeto del entorno. }\end{array}$ \\
\hline Propósito & $\begin{array}{l}\text { Construir y entender situaciones de acuerdo con las necesidades del } \\
\text { individuo. }\end{array}$ \\
\hline
\end{tabular}

\begin{tabular}{cl}
\hline Proceso & $\begin{array}{l}\text { La percepción realiza constantemente un proceso dinámico y continuo } \\
\text { en el tiempo y el espacio para crear o recodar situaciones internas o } \\
\text { externas en pro de una solución. }\end{array}$ \\
\hline Relatividad & $\begin{array}{l}\text { Dentro de la percepción no existe lo absoluto ya que esta se adapta a la } \\
\text { situación presentada por el estímulo percibido por el sujeto. }\end{array}$ \\
\hline
\end{tabular}

Fuente: Elaboración Propia (2020).

\section{Teoría de Gestalt - Moodle}

La teoría de Gestalt sirve de base para activar el interés del estudiante en primera instancia desde la percepción virtual que otorga la generación de un curso en Moodle. Al ser la percepción una causa y un efecto del aprendizaje es necesario captar la atención del sujeto, ofreciendo un abanico de opciones para que él, desde el autoaprendizaje logre los objetivos trazados y evalúe el progreso respecto a los mismos, Pupiales (2009) afirma que:

Al hablar de aulas virtuales, normalmente se hace relación a las múltiples posibilidades y experiencias culturales que ofrece Internet, por ejemplo: desarrollo curricular, desarrollo del aprendizaje, de espacios sociales tales como los foros virtuales, la wiki, o sea, espacios democráticos en donde los estudiantes a través de una temática o problema a abordar, reflexionan y debaten con el propósito de construir dominios consensuales más ricos, significativos y profundos con el colectivo, verbigracia, para elaborar un texto ensayo, como fruto de la discusión del colectivo social y mediante la red de conectividad (p.83).

En este orden de ideas, Moodle es una herramienta que controla el proceso de aprendizaje del sujeto desde la elaboración de contenidos, por lo que la estructuración de espacios colaborativos permite construir conocimiento y organizar en lapsos de tiempo los temas y/o actividades que se encargan de lograr los objetivos trazados basados en el respeto, la responsabilidad y la honestidad como principios básicos de interacción entre el sujeto, el docente y el ambiente virtual.

De acuerdo con lo anterior, Ros (2008) afirma que la plataforma:

Fomenta el autoaprendizaje, el aprendizaje cooperativo y la creatividad, facilitando la participación e implicación de unos alumnos con un 
perfil diferente al tradicional y que precisan que las actividades que realizan les motiven y que tengan relación con lo que están aprendiendo y la realidad laboral en donde aplicaran esos conocimientos (p.8).

Las asignaturas virtuales de la Universidad de Pamplona están estructuradas dentro de la plataforma Moodle, con actividades programadas como foros, mapas mentales, trabajos colaborativos, comunicación sincrónica y asincrónica entre estudiantes y docentes mediante mensajería, videoconferencias, correo electrónico, videos, audios, envío de trabajos investigativos en la plataforma, etc., para ser entregadas en un lapso de tiempo establecido por el docente. Es así, que la práctica educativa de interacción que ofrece Moodle corresponde con las concepciones que, de esta, se tienen desde diferentes autores, quienes plantean que "es una herramienta polivalente que favorece un amplio abanico de posibilidades de comunicación didáctica" Correa, (2005).

\section{E-Learning.}

Rosemberg (2002) plantea "la educación e-learning como el uso de las tecnologías basadas en internet para proporcionar un amplio despliegue de soluciones a fin de mejorar la adquisición de conocimientos y habilidades" (p.4). Lo anterior implica, que la virtualidad en la educación deba cumplir con algunos criterios o aspectos mínimos, como que se ejecute bajo los parámetros de interconexión de internet, que llegue al estudiante y docente a través de un computador y que se centre en la solución de situaciones a través de paradigmas diferentes a los utilizados en la formación tradicional. Gesa (2012) afirma que:

Mediante el uso de las tecnologías de la información, los procesos de formación han dejado de tener límites de espacio o tiempo, debido a que en la actualidad los estudiantes aprenden no sólo con los materiales tradicionales disponibles, sino que también lo hacen con las destrezas relacionadas con el encontrar, evaluar e interpretar los contenidos que estudian cuando se relacionan con el mundo real (p.83).
Por otra parte, García (2005) considera que el e-learning es una capacitación no presencial que, a través de plataformas tecnológicas, viabiliza y adapta el acceso y el tiempo en el proceso de enseñanza-aprendizaje, adecuándolos a las habilidades, necesidades y disponibilidades de cada discente, además de avalar ambientes de aprendizaje colaborativos mediante el uso de herramientas de comunicación síncrona y asíncrona, fomentando en suma el proceso de gestión basado en competencias.

Tabla 3. Formación Virtual

\begin{tabular}{|c|c|}
\hline Fases del Ciclo de Vida & Descripción \\
\hline Planeación & $\begin{array}{l}\text { En esta fase se define la asignatura, la población, los objetivos, los } \\
\text { recursos y el material necesario para el desarrollo. Es esta fase solo } \\
\text { intervienen las autoridades académicas. }\end{array}$ \\
\hline Diseño del curso virtual & $\begin{array}{l}\text { En esta fase se define el contenido a desarrollar y los recursos } \\
\text { didácticos que se utilizaran para un óptimo proceso de enseñanza - } \\
\text { aprendizaje. Es importante que en esta fase puedan intervenir los } \\
\text { diferentes actores del proceso como: autoridades académicas, docentes } \\
\text { y estudiantes. }\end{array}$ \\
\hline $\begin{array}{c}\text { Desarrollo de entornos y contenidos } \\
\text { digitales }\end{array}$ & $\begin{array}{l}\text { En esta fase los expertos en desarrollo de contenidos elaboran cada uno } \\
\text { de los recursos establecidos en la fase de diseño. }\end{array}$ \\
\hline Fase de pruebas & $\begin{array}{l}\text { En esta fase el grupo experto conformado por docentes y estudiantes } \\
\text { ejecutará y evaluará el contenido de la asignatura con el fin de } \\
\text { establecer mejoras o avalarlo para su puesta en producción }\end{array}$ \\
\hline $\begin{array}{l}\text { Puesta en producción del curso virtual } \\
\text { como herramienta de enseñanza - } \\
\text { aprendizaje }\end{array}$ & $\begin{array}{l}\text { En esta fase el curso virtual es colocado al servicio de los docentes y } \\
\text { estudiantes para su desarrollo académico. }\end{array}$ \\
\hline Evaluación del curso & $\begin{array}{l}\text { En esta fase se debe evaluar por los actores que intervienen en el } \\
\text { proceso con el fin de retroalimentar y establecer mejoras para el } \\
\text { siguiente periodo académico. }\end{array}$ \\
\hline
\end{tabular}

Tabla 4. Percepciòn y Educación Virtual

\begin{tabular}{|c|c|c|c|}
\hline \multicolumn{4}{|c|}{ Estrategia } \\
\hline \multicolumn{4}{|c|}{$\begin{array}{l}\text { Organizar estudiantes en pequeños grupos, a estos grupos se les presentan disímiles ejemplos o enfoques } \\
\text { de un concepto para que intercambien opiniones y formulen sus hipótesis con la finalidad de convenir } \\
\text { un acuerdo concluyente con respecto al tema de estudio. }\end{array}$} \\
\hline \multicolumn{4}{|c|}{ Formas de intercambiar información } \\
\hline \multirow{3}{*}{ SINCRÓNICA } & $\checkmark \quad$ Foros & \multirow{3}{*}{ ASINCRÓNICA } & $\checkmark$ Correo \\
\hline & $\checkmark$ Chat & & $\checkmark$ Foros \\
\hline & $\checkmark \quad$ Aulas virtuales & & $\checkmark$ Blogs \\
\hline RECURSOS & & $\begin{array}{ll}\checkmark & \text { Gráficos, } \\
\checkmark & \text { Animaciones } \\
\checkmark & \text { Sonidos. } \\
\end{array}$ & \\
\hline
\end{tabular}

Fuente: Vivas, (2011). Modelos pedagógicos en educación a distancia.

El Concentrar las TIC y las Comunidades Virtuales de Aprendizaje (CVA) en el proceso de enseñanza, genera situaciones nuevas de aprendizaje y oportunidades de intercambio de conocimiento entre los diferentes actores, lo cual permite transpolar situaciones para llegar a soluciones de forma conjunta en lo que respecta a procesos educativos.

Teniendo en cuenta lo anterior y para el mejor aprovechamiento de estos ambientes de aprendi- 
zaje se deben utilizar estrategias que fortalezcan el proceso formativo y mantengan al estudiante motivado en el transcurso de las asignaturas o programas según sea el caso, Cacheiro (2014) señala que las estrategias de enseñanza "son un proceso de ayuda que se va ajustando en función de cómo ocurre el progreso en la actividad constructiva" (p. 45), en consecuencia, las estrategias son la forma en que se enseña y la forma en que los alumnos aprenden a aprender por ellos mismos, y por su parte, Galvis (2017), expone que son una guía para todos los que incursionan en el maravilloso mundo del aprendizaje.

Tabla 5. Procesos Pedagógicos y Elementos del Aula Virtual Universidad de Pamplona

\begin{tabular}{|c|c|c|c|}
\hline \multirow{2}{*}{\multicolumn{2}{|c|}{$\begin{array}{c}\text { Procesos } \\
\text { pedagógicos }\end{array}$}} & \multirow{2}{*}{\multicolumn{2}{|c|}{ 1. Inicio del aprendizaje }} \\
\hline & & & \\
\hline 1.1 & Motivación & $\begin{array}{l}\text { Acción permanente en el que se } \\
\text { generan para el estudiante las } \\
\text { condiciones de interés necesarias para } \\
\text { un óptimo proceso de enseñanza - } \\
\text { aprendizaje. }\end{array}$ & $\begin{array}{l}\text { (Video e información de } \\
\text { presentación, Banner de } \\
\text { presentación de la asignatura } \\
\text { virtual) } \\
\text { (Banner de presentación de la } \\
\text { asignatura virtual) }\end{array}$ \\
\hline 1.2 & $\begin{array}{l}\text { Recuperación de } \\
\text { saberes previos }\end{array}$ & $\begin{array}{l}\text { Conocimientos previos con que el } \\
\text { estudiante llega a desarrollar un curso. }\end{array}$ & $\begin{array}{lcc}\text { (Material de } & \text { estudio } & y \\
\text { complementario) } & & \\
\end{array}$ \\
\hline 1.3 & Conflicto cognitivo & $\begin{array}{l}\text { Rompimiento de las estructuras } \\
\text { mentales debido a la no comprensión } \\
\text { y/o explicación de saberes propios. }\end{array}$ & $\begin{array}{l}\text { (Información General) } \\
\text { (¿Tema de la semana, Al finalizar } \\
\text { este tema usted?, Guía de } \\
\text { aprendizaje). }\end{array}$ \\
\hline 2. & $\begin{array}{l}\text { Construcción del } \\
\text { aprendizaje }\end{array}$ & $\begin{array}{l}\text { Proceso mediante el cual se } \\
\text { desarrollan estructuras cognitivas a } \\
\text { través de una entrada, construcción y } \\
\text { salida de información. }\end{array}$ & (Actividades de aprendizaje) \\
\hline 3. & $\begin{array}{c}\text { Aplicación y/0 } \\
\text { transferencia del } \\
\text { aprendizaje } \\
\end{array}$ & $\begin{array}{l}\text { Solución de situaciones nuevas a } \\
\text { través de la ejecución de la teoría y } \\
\text { conceptualización adquirida. }\end{array}$ & (Actividades de aprendizaje) \\
\hline & & 4. Metacognición y evaluación & \\
\hline 4.1 & Reflexión & $\begin{array}{l}\text { Retroalimentación entre lo aprendido } \\
\text { y ejecutado para establecer mejora } \\
\text { continua en el proceso de aprendizaje. }\end{array}$ & $\begin{array}{l}\text { (Comunicaciones, Notificaciones } \\
\text { y mensajería) } \\
\text { (Interacción, Notificaciones y } \\
\text { mensajería) }\end{array}$ \\
\hline 4.2 & Evaluación & $\begin{array}{l}\text { Determinación de aciertos y } \\
\text { desaciertos dentro del proceso de } \\
\text { enseñanza-aprendizaje. }\end{array}$ & (Actividades de aprendizaje) \\
\hline
\end{tabular}

Fuente: Elaboración Propia (2020).

\section{E-Learning como Herramienta de Aprendizaje}

La enseñanza virtual u online (e-learning) es definida por la Fundación para el Desarrollo de la Función Social de las Comunicaciones (FUNDESCO), tal como lo señala Marcelo, Puente y Ballestero (2002, p.5) como "un sistema de impartición de formación a distancia, apoyado en las TIC que combina distintos elementos pedagógicos: instrucción clásica (presencial o autoes- tudio), las prácticas, los contactos en tiempo real (presenciales, videoconferencias o chats) y los contactos diferidos (tutores, foros de debate, correo electrónico)". Así mismo, Urdan y Weggen (2000, p. 10) definen el e-learning como el desarrollo de contenidos a través de cualquier medio electrónico incluyendo Intranet, Extranet, satélites, cintas de audio video, televisión interactiva y CD-ROM. En cambio, para Castells (2001, p.21) el e-Learning "es la respuesta que el mundo de la educación y el de la tecnología han desarrollado en conjunto para adaptar a las organizaciones sociales a las reales necesidades que requieren los actores del mundo globalizado basado en el conocimiento y en el capital humano". Por otro lado, Boneu (2007, p. 3) define el e-learning como "una forma de utilizar la tecnología para distribuir materiales educativos y otros servicios, permitiendo establecer un canal de retorno entre profesores y alumnos".

Por otra parte, la enseñanza virtual aporta unas ventajas al ofrecer métodos, técnicas y recursos que hacen más efectivo, flexible el proceso de enseñanza-aprendizaje y que pueden justificar su rápida expansión; la posibilidad de utilizar materiales multimedia, la fácil actualización de los contenidos, la interactividad, acceso al curso desde cualquier lugar y en cualquier momento, la existencia de un feed-back de información inmediato, de manera que un profesor conoce si el alumno responde al método y alcanza los objetivos fijados inicialmente. En otras palabras, la enseñanza virtual a través de Ambientes Virtuales de Aprendizaje (AVA) está referido a las organizaciones, comunidades, actividades y prácticas que operan y tienen lugar en Internet; y se subraya su potencialidad por permitir una comunicación entre usuarios, similar a la que se realiza cara a cara, (Coll, 2008).

De esta forma, para Iazza y Pinzón (2005, p.17) el e-Learning apuesta por un tipo de modelo educativo en el que el alumno tiene un papel principal como parte activa del proceso de aprendizaje. Su relación con el profesor ya no será de mero oyente, sino que las herramientas de comunicación que ofrece Internet (foros, chats, etc.) le dan la posibilidad de interaccionar con el tutor, con 
los demás alumnos y con el propio sistema. Todos los elementos que forman parte del modelo pedagógico virtual se ponen a disposición del estudiante para que pueda gestionar su propio proceso formativo. Por lo anterior, para Rodríguez y Vaca (2018, p.72) "el aprendizaje nunca llega a ser un proceso completo, sino que continuamente los individuos adaptan y reelaboran el conocimiento que proviene del mundo real a partir de las diversas fuentes de información que emplean". Para optimizar este modelo hay que tener presente dos aspectos cruciales: la calidad pedagógica (de los materiales virtuales diseñados y de la metodología docente empleada) y el énfasis en el apoyo personalizado. Por lo anterior, para Díaz y Ledesma (2011, p.3) al desear diseñar un recurso educativo indistintamente de la aplicación que se emplee, es necesario reconocerla como estrategia pedagógica. Al mismo tiempo, el alumno desarrollará una importante actividad de dinamización y creación de información pues, como usuario de Internet, puede proponer y sugerir recursos educativos, intercambiando éstos con sus compañeros en línea.

\section{Materiales y Métodos}

\section{Participantes}

Los informantes claves son de uso fundamental para el desarrollo inicial del objeto de estudio, puesto que orientan el proceso de investigación, para Taylor \& Bogdam (1986) "apadrinan al investigador en el escenario y son sus fuentes primarias de información" (p.5); es decir, los informantes claves poseen la capacidad de empatizar y relacionarse con el campo donde interactúa y pueden acoger al investigador convirtiéndose en una fuente importante de información. Martínez (2009), asegura que los informantes clave son personas con conocimientos especializados, capacidad para proporcionar la información requerida.

Sin embargo, se debe tener claridad que en una etapa más avanzada cumple con la función de cubrir faltantes de información y evidenciar aspectos que no han sido detectados para los inves- tigadores. En este orden de ideas, para la presente investigación se tomó la cantidad de siete (7) estudiantes seleccionados aleatoriamente, matriculados para el periodo 2020-1 en las asignaturas virtuales de los cursos de Formación Ciudadana y Cultura de la Paz, y Educación Ambiental de la Universidad de Pamplona, sede Villa del Rosario, Norte de Santander, Colombia.

\section{Tipo de estudio}

La investigación se basó en la filosofía post positivista bajo un enfoque cualitativo el cual se basa en el contexto natural de la realidad, tal y como sucede en las asignaturas virtuales de la Universidad de Pamplona. En tal sentido Gonzáles (2013), refiere que, la investigación cualitativa aborda lo real en cuanto proceso cultural, desde una perspectiva subjetiva, con la que se intenta comprender e interpretar todas las acciones humanas, las vivencias, las experiencias, el sentir, con el fin de crear formas de ser en el mundo de la vida.

Por otra parte, Bernal, (2006), afirma que el estudio cualitativo requiere de una observación próxima y detallada del sujeto en su propio contexto, para lograr aproximarse lo más posible a la significación de los fenómenos.

En este sentido, Andrade y Bracho (2019), señalan que es sustancial reflexionar acerca de lo que es investigar a partir de las experiencias propias, que llevarán a una explicación acerca de lo que se hace, lo que se piensa y cuál es su fin o propósito. Por lo que, la investigación cualitativa permite una perspectiva centrada en el entendimiento de la interpretación de lo que el sujeto va captando en el entorno, que, para el caso de estudio, son las aulas virtuales en la plataforma Moodle de la Universidad de Pamplona.

Tabla 6. Descripción de los informantes asignaturas virtuales de la Universidad de Pamplona

\begin{tabular}{cc}
\hline Asignaturas virtuales de la Universidad de Pamplona & Cantidad \\
\hline Formación Ciudadana y Cultura de la Paz & 4 \\
Educación Ambiental & 3 \\
\hline Total & 7 \\
\hline
\end{tabular}

Fuente: Elaboración Propia (2020). 
De igual manera, se acudió al investigador experto que lidera el estudio, para realizar un análisis estructural a las aulas virtuales, desde la observación de su diseño y actividades de ejecución.

\section{Instrumento}

Los instrumentos en un trabajo de investigación son utilizados por los investigadores para recolectar información, teniendo en cuenta la muestra seleccionada, y así mismo lograr resolver el problema del objeto de estudio, según Arias (2012) "son las distintas formas o maneras de obtener información, señalando que los instrumentos son medios materiales que emplean para recoger y almacenar información" (p.146), por tal motivo permiten conseguir unos resultados específicos que aportan una información de alta importancia para el presente trabajo. Por otra parte, Bracho (2012), señala que las técnicas son los recursos utilizados para facilitar la recolección y el análisis de los hechos. En tal sentido, se realizó una observación directa a las aulas virtuales objeto de estudio, mediante la aplicación de un diario de campo por parte del experto investigador, teniendo en cuenta los principios de la Gestalt que fundamentan el presente interés investigativo.

Para la recolección de los datos se utilizó una encuesta, aplicada a los siete (7) estudiantes seleccionados aleatoriamente, con el fin de acercarse a estos de manera ética y recabar la mayor cantidad de información a través de un conjunto de preguntas abiertas, orientadas en los nueve (9) principios o leyes de Gestalt, y con un desarrollo a manera de conversación, con el objetivo de obtener las respuestas necesarias que sirvan de insumo para la validación de la estructura gestáltica de los diferentes cursos virtuales de la Universidad de Pamplona, desde la percepción del estudiante.

\section{Procedimiento}

Para el desarrollo de la presente investigación se han tenido en cuenta tres fases importantes que estructuran todo proceso de investigación: ob- servación, recolección de la información, y análisis e interpretación, ya que en este proceso según, Hernández, Fernández y Baptista (2014), se posibilita el acercamiento objeto-sujeto de investigación dando de esta forma alternativas factibles de solución a las problemáticas reconocidas e identificadas por el investigador.

\section{Momento 1. Observación}

Significa observar un objetivo claro, concreto y preciso: el investigador sabe que es lo que quiere observar y para que quiere hacerlo, lo cual implica que debe preparar cuidadosamente la observación. Sierra (2001), la define como: "la inspección y estudio realizado por el investigador, mediante el empleo de sus propios sentidos, con o sin ayuda de aparatos técnicos, de las cosas o hechos de interés social, tal como son o tienen lugar espontáneamente"

Este momento permitió construir una estructura del problema y recolectar la información necesaria para iniciar con un planteamiento que luego se va acotando en la medida que avanza la investigación, de tal modo que el estudiante busca establecer lo que se define como la situación problematizadora lo que desencadena en un posible título y objetivo general que serán la base del proyecto. Según Schuster et al., (2013), durante este primer momento se ha requerido de pasos que permitieran fijar prioridades, definir estrategias y garantizar la toma de decisiones en torno a la situación planteada. Así mismo, se realiza la revisión de antecedentes, bibliografía, datos estadísticos y referentes legales como eje conductor durante el proceso de la investigación y ejecución del proyecto.

\section{Momento 2. Recolección de información}

La recolección de la información, consiste en los medios que emplea el investigador para recoger de forma minuciosa y detallada las pesquisas o datos que suministren los informantes claves. Méndez (1999, p.143) define a las fuentes para recolección de la información como los hechos o documentos a los que acude el investigador y que 
le permiten tener información.

En este momento se realizó la recolección de la información referente al problema objeto de estudio, la cual permitió contar con una visión clara de la realidad percibida por el experto investigador y los estudiantes que cursan asignaturas virtuales en la Universidad de Pamplona a través de técnicas e instrumentos establecidos para tal fin.

\section{Momento 3. Análisis e interpretación}

El análisis y la interpretación consistieron básicamente en dar respuesta a los objetivos pautados en la investigación con función explicativa. Según, Zorrilla y Torres (1992, p.77) consiste en interpretar los resultados obtenidos con la ayuda de los instrumentos construidos para ello, por otra parte, Balestrini (2003: 73), señala que "se debe considerar que los datos tienen su significado únicamente en función de las interpretaciones que les da el investigador, ya que de nada servirá abundante información si no se somete a un adecuado tratamiento analítico", es decir, se trata de encontrar un significado más amplio de la información.

En este momento se realizó el análisis de la información recopilada a partir de las técnicas e instrumentos aplicados que permitieron hacer una descripción, interpretación y explicación comprensiva de la realidad actual de los estudiantes que cursan asignaturas virtuales en la Universidad de Pamplona Sede Villa del Rosario para consolidar la situación problema.

\section{Confidencialidad o consentimiento informado}

En lo que respecta a la confidencialidad del proceso investigativo es recurrente asistir a los principios éticos, el cual se tomó en consideración del código de ética profesional de psicólogos, citado por Tojar \& Serrano (2000), de los deberes éticos en el área de investigación, ya que este contemplo el consentimiento informado como parte del proceso investigativo a fin de proteger los derechos, dignidad y la integridad de los sujetos sometidos al estudio.
El consentimiento informado se enmarcó en la capacidad del investigador de informar y hacer comprender a los estudiantes que cursan las asignaturas virtuales de Formación Ciudadana y Cultura de la Paz, y Educación Ambiental de la Universidad de Pamplona, sede Villa del Rosario, Norte de Santander Colombia, la importancia de evaluar las aulas virtuales construidas bajo la plataforma Moodle con respecto a las características perceptivas que posibilitan dichos los cursos desde la perspectiva de la teoría de la Gestalt, a fin de mantener un equilibrio entre la discreción, la información y apuntar a las mejores respuestas y el menor riesgo posible en la confidencialidad de la información.

\section{Resultados}

La Tabla 7 muestra los niveles de análisis que se utilizan en el proyecto de investigación con el fin de determinar la incidencia de la Teoría de Gestalt en la percepción de los estudiantes de la Universidad de Pamplona.

Tabla 7. Definición de niveles de análisis y categorías

\begin{tabular}{cc}
\hline Nivel de análisis & Categorías \\
\hline Percepción & Inferencial \\
& Proceso \\
Insight \\
Atención \\
Experiencia \\
\hline Estructura & Principio de figura-fondo \\
& Principio de Sencillez \\
& Principio de Proximidad \\
& Principio de Similaridad \\
& Ley de cierre \\
& Principio de Continuidad \\
\hline
\end{tabular}

Fuente: Elaboración Propia (2020).

El propósito de esta investigación se enfocó en evaluar las características perceptivas que posibilitan los cursos de Formación Ciudadana y Cultura de la Paz, y Educación Ambiental en el marco de las asignaturas virtuales (Moodle) en los programas de pregrado de la Universidad de Pamplona, Sede Villa del Rosario, desde la perspectiva de la teoría de la Gestalt, permitiendo desde el enfoque cualitativo la aplicación de instrumentos que llevaron a realizar una revisión 
perceptiva de la estructura de estas aulas virtuales, a partir de la mirada del experto investigador (diario de campo) y del estudiante (encuesta).

En este sentido, se describe en primera instancia los resultados obtenidos, en la que se estableció una categoría para cada aspecto. Con relación a la categoría Inferencial se obtuvo que el aula Moodle construida para las asignaturas virtuales estimula en varios aspectos el nivel sensorial (vista y oído) del usuario, pero no son representativos, ya que visualmente no se denota una identidad institucional en cuanto a imágenes, colores y estructura, mostrando una interface plana y poco llamativa para este. Por su parte, los sonidos de los videos de presentación no están acordes con las imágenes mostradas y el sonido lector de las lecturas principales es robotizado. Lo anterior, rompe con lo planteado para esta primera categoría acorde a las características del sujeto dentro del proceso de percepción, que es muy importante puesto que "inicialmente determina la entrada de información; y en segundo lugar, garantiza que la información retomada del ambiente permita la formación de abstracciones (juicios, categorías, conceptos, etc) (Gilberto, 2004, p.90), lógicamente incidiendo en mejores procesos de aprendizaje.

En lo que corresponde a la categoría Proceso se encontró que el aula Moodle construida permite ejecutar secuencialmente las actividades dentro del curso ya que cada hito se encuentra organizado en bloques y su secuencia lineal de arriba hacia abajo permite al usuario culminar satisfactoriamente el proceso académico dentro de la semana de trabajo.

Para la categoría Insight se resalta la falta de un punto de inflexión que le permita al usuario mantener su atención en el curso y a estar buscando los elementos y/o estímulos no logrados dentro de su proceso académico para convertirlos en una fuerza motivadora de cambio no solo para obtener un resultado numérico de aprobación sino un resultado académico integral para su formación como ser humano. De aquí, la necesidad de establecer estrategias de enseñanza que funjan como "un proceso de ayuda que se va ajustando en función de cómo ocurre el progreso en la acti- vidad constructiva" (Cacheiro, 2014, p. 45), para lograr consolidar la atención del estudiante en los contenidos de aprendizajes abordados.

En cuanto a la categoría Atención se observó que el aula Moodle es simple y plana, carente de elementos interactivos, animaciones, imágenes personalizadas, postcast, etc, es decir, ampliar el espectro metodológico académico de acuerdo con las nuevas Tecnologías de la Información y Comunicación TIC, con el fin de mantener motivado al usuario en su proceso de enseñanza aprendizaje. Pineda, Casanova \& Bracho, (2020), afirman que las tecnologías son esenciales para favorecer el desarrollo de las dimensiones y competencias en todo proceso de cambio e innovación, los cuales solventan los requerimientos actuales de una sociedad globalizada.

En lo pertinente a la categoría Experiencia en palabras de Larrosa (2006) la experiencia es "eso que me pasa" (p.88) se encontró que el aula Moodle se fundamenta en la habilidad de ejecución empírica de la unidad UETIC sin tener en cuenta para su diseño una fundamentación teórica estructurada que permita al usuario un aprendizaje significativo y un mejor acoplamiento a los Ambientes Virtuales de Aprendizaje -AVA, evitando de esta manera la pérdida o cancelación de este tipo de asignaturas. Esto, evidencia claramente una desventaja en la estructuración de las aulas virtuales, y las posibilidades de acción de e-learning en plataformas tecnológicas como Moodle, que posibilitan y flexibilizan el acceso y el tiempo en el proceso de enseñanza- aprendizaje, adecuándolos a las habilidades, necesidades y disponibilidades de cada discente, además de garantizar ambientes de aprendizaje colaborativos mediante el uso de herramientas de comunicación síncrona y asíncrona, potenciando en suma el proceso de gestión basado en competencias García, (2005).

Por otra parte, se relacionan los resultados obtenidos a partir de la percepción de los estudiantes, en las categorías establecidas, teniendo en cuenta los aspectos de video, información general, guía de lectura, lectura principal, guía de aprendizaje y presentación de la semana. 
Respecto a la categoría de Figura y Fondo de la Gestalt, el aula Moodle es percibida por el estudiante como una estructura donde no existe una figura que predomine en cada uno de los elementos mencionados, lo cual, al hacer contraste con el fondo en cada uno de los contextos planteados, el usuario pierde la percepción principal del momento, invitándolo a la dispersión y al desinterés al momento de ejecutar las acciones de aprendizaje dentro del aula. Lo anterior, evidencia poca cercanía de acuerdo a lo planteado por la Gestalt en lo que se refiere a Figura y Fondo, y su relación directa con la percepción, puesto que; las diferencias entre figura y fondo son muy significativas. La figura se caracteriza por tener una forma muy definida, fácilmente ubicable espacio-temporal. La presencia de contornos permite darle a la figura cualidades tan importantes como relieve, tamaño, textura y fácilmente referir a un interior y a un exterior. El fondo, por el contrario, carece de límites o contornos, tiene un carácter indefinido y tiende a hacerse cada vez más homogéneo con respecto a la figura. Gilberto, (2004, p.95).

En relación con la estructura del curso con respecto a la categoría de Sencillez de la Gestalt, el aula Moodle es percibida por el estudiante como una estructura no óptima organizativamente, debido a que en algunos casos no se tiene un buen contraste visual e intervienen elementos distractores que generan en el usuario ambigüedad en su interpretación y percepción a la hora de ejecutar las actividades propias de cada curso. Según la Gestalt, "una buena forma (buena Gestalt) es la que está bien articulada. Tiende a dejar su huella en el observador, a persistir, a recurrir" (Boring, 1992, citado por Gilberto, 2004, p.93).

En cuanto a la categoría de Proximidad de la Gestalt, los estudiantes percibieron una clara agrupación de elementos que le permiten al usuario entender más fácilmente el contexto, debido a que ciertas imágenes y grafías están cercanas y relacionadas entre sí y vinculadas o inmersas las unas con las otras, lo cual permite entender un gráfico o rotulo de manera holística y con mayor facilidad. De acuerdo a Gilberto (2004) "La distribución espacial de los objetos es uno de los más importantes criterios para realizar el traba- jo de abstracción. La variable distancia entre los elementos permite llevar a cabo la organización perceptual" (p. 93).

En lo que corresponde con la categoría de Similaridad de la Gestalt, se encontró que es percibida por el estudiante como una estructura dispersa y poco asociativa dado que no encuentra regularidad en patrones similares pertinentes en color, forma, tamaño, estructura, contraste, estilo en la grafía e imágenes y elementos significativos dentro de los diferentes recursos lo que dificulta al usuario ver las cosas como un todo dentro de la estructura del aula. Esto evidencia posibles debilidades para la adquisición de información adecuada para el aprendizaje, pues no se articula a los postulados de este principio, que plantea dentro de la Gestalt que "la percepción clasifica la información según el grado de semejanza que mantengan los estímulos entre sí" Gilberto, (2004, p. 94).

Respecto a la categoría de Cierre de la Gestalt, se puede decir que el aula Moodle es percibida por el estudiante como una estructura en la que la mayoría de los casos se encuentran elementos no completos a nivel de ejecución, indicaciones, ideas, transiciones, imágenes, mensajes, conclusiones, etc., formando en el usuario una noción vaga y vacía al momento de interpretar y contrastar un elemento, una situación, un contexto, una lectura, una interfaz con su conocimiento previo. Dado que algunos elementos dentro del curso no tienen un cierre, se puede decir que están incompletos, lo que lleva a los usuarios a invertir mayor cantidad de tiempo para su entendimiento lo que conlleva a generar indirectamente una percepción con un significado erróneo al que se quiso plantear dentro del curso. En este sentido, se observa la poca relación con este principio de la Gestalt, concebido como aquel en el que "toda información que contribuya a la conformación del concepto de contorno es privilegiada por sobre aquella que no contribuye a darle bordes o límites definidos a los objetos" Gilberto, (2004, p. 94) y que directa o indirectamente, infiere en procesos de aprendizaje, que parten de la capacidad de percepción visual que se tiene sobre la información que se recibe del entorno. 
Finalmente, en relación con la categoría de Continuidad, los estudiantes perciben un aspecto sinérgico o trabajo en conjunto, no solo encaminado a completar el objetivo académico de aprobar el curso sino de mejorar en la concepción del estudiante como ser humano en el aspecto cívico y ambiental. Al analizar las respuestas de continuidad, "Completar partes faltantes haciendo creer que lo que no se ve, sigue estando ahí mismo, de igual manera se llega a conceptuar que lo no visible es similar a lo que vemos" (López, 2016, p.16).

\section{Conclusiones}

En el estudio se llegó a las diversas conclusiones, siendo una de ellas que la aplicación de una fundamentación teórica como la de Gestalt, mejoraría significativamente la percepción del estudiante referente a los cursos de formación Ciudadana y Cultura de la Paz y Educación Ambiental en el marco de las asignaturas virtuales (Moodle) y permitiría construir una base con estándares audiovisuales idóneos.

Las asignaturas virtuales se construyeron $\sin$ tener en cuenta una identidad institucional teniendo como referencia una semilla, la cual fue diseñada de forma empírica y sin una fundamentación que permita el aprendizaje significativo de los estuantes que toman dichos cursos.

Los recursos audiovisuales y elementos constitutivos del aula deben ser construidos atendiendo el primer plano de estímulo visual sensorial del Principio de Figura-Fondo de la Gestalt, captando la atención del estudiante con elementos contrapuestos de las tecnologías emergentes, con el fin de permitir una mejor interactividad entre el aula y los actores que intervienen en ella.

La guía de lectura y aprendizaje debe ser un elemento que genere un punto de inflexión en el estudiante y construida mediante la orientación del Principio de Sencillez de la Gestalt sin elementos distractores y con un adecuado arreglo visual que involucre una herramienta interactiva que le permita secuencializar las instrucciones de ejecución de una forma más fácil y sencilla.

La lectura principal debe estar enmarcada dentro del Principio de Proximidad de la Gestalt dado que debe ser un elemento que condense el tema general y permita mediante aristas entrelazar ideas y demás lecturas con el fin de captar la atención del estudiante y generar una base investigativa que profundice en el tema en discusión y los demás temas vinculados.

El aula Moodle diseñada para las asignaturas de manera estructurada y organizada estimula medianamente a nivel sensorial (Vista y oído) al estudiante dado que visualmente no se percibe una identidad institucional en cuanto a imágenes, colores y contraste y carece de animaciones y procesos interactivos mostrando una interface plana y poco llamativa que impidiendo la captación de la atención del usuario.

El aula permite ejecutar las actividades dentro del curso y cerrarlas dentro del proceso académico dada la organización en bloques y la secuencia lineal estructurada; sin embargo, falta desde el docente diseñar nuevos procesos y recursos académicos mediante la utilización de TIC, que generen sinergia y complexión entre el material de estudio y el complementario.

El nivel perceptivo del Insight dentro del aula no está definido, lo que impide al estudiante mantener su atención en el curso y buscar los elementos y/o estímulos no logrados dentro del proceso académico para convertirlos en una fuerza motivadora de cambio, no solo para aprobar una asignatura sino para lograr un resultado académico integral.

El curso diseñado bajo la plataforma Moodle es simple y plano, carente de elementos interactivos, animaciones, imágenes personalizadas, postcast, etc, lo cual dificulta ampliar el espectro de aprendizaje, facilita la dispersión de la atención desmotivando al estudiante en su proceso de enseñanza aprendizaje y retrasa el avance académico con respecto a las demás asignaturas del pensum. El concepto de amplitud dentro del aula de estudio debe extenderse involucrando las nuevas Tecnologías de la Información y Comunicación (TIC), con el fin de relacionarlos entre si y mantener la proximidad entre elementos textuales y/o gráficos permitiendo una agrupación del conocimiento y una memorización perceptiva del contexto. 
El aula Moodle diseñada se fundamentó en la habilidad de ejecución empírica de la Unidad Especial para el uso y apropiación de las TIC UETIC sin tener en cuenta para su diseño una fundamentación teórica estructurada que permita al estudiante un aprendizaje significativo y un mejor acoplamiento a los Ambientes Virtuales de Aprendizaje (AVA) evitando de esta manera, la pérdida o cancelación de este tipo de asignaturas.

Los resultados del proceso de investigación para las asignaturas virtuales de la Universidad de Pamplona recomienda La Teoría de Gestalt como fundamento estructural perceptivo para el mejoramiento de la semilla de cada uno de los cursos virtuales de la Universidad de Pamplona, lo cual lleva a generar un plan de capacitaciones a los docentes para que el contenido inyectado a cada semilla se fundamente dentro de los parámetros establecidos dentro de la misma. Así mismo es importante aplicar las categorías de estudio a otros elementos como comunicaciones, evaluaciones y actividades, lo cual permitirá a futuro motivar al docente y al estudiante a utilizar los recursos tecnológicos de forma creativa en aras de mejorar el aprendizaje significativo de cada uno en el contexto de desarrollo académico que se encuentre.

\section{Referencias Bibliográficas}

Andrade, J. \& Bracho, K. (2019). Concepción Docente frente a la Formación Integral de los Educandos en Hogares, Comunitarios. CIE, 2(8), 38-53.

Antón, L. (2011). Teorías del aprendizaje en educación superior: Teorías contemporáneas del aprendizaje. https://coscomantauni.files.wordpress.com/2011/09/teorias-del-aprendizaje.pdf.

Arias, F (2012) El Proyecto de Investigación. Introducción a la investigación científica. Caracas. 6ta ed. Venezuela: Editorial Episteme.

Balestrini, M. (2003). Estudios Documentales, Teóricos, Análisis de Discurso y las Historias de Vida: una propuesta metodológica para la elaboración de sus proyectos. (2a. ed.) Caracas: BL Consultores Asociados. Servicio Editorial.

Bernal, C. (2006). Metodología de la Investigación. México, D.F., Pearson educación.

Boneu, J. (2007). Plataformas abiertas de e-learning para el soporte de contenidos educativos abiertos. RUSC. Universities and Knowledge Society Journal, 4(1), 36-47. https:// doi.org/10.7238/rusc.v4i1.298

Boring, E. (1992). Historia de la psicología experimental. México: Trillas.

Bracho (2012). Cultura Investigativa y Producción Científica en Universidades Privadas del Municipio Maracaibo del Estado Zulia. REDHECS. Vol. 7. pp. 50-69.

Cacheiro, M. (2014). Educación y Tecnología: Estrategias didácticas para la integración de las TIC. Madrid: Editorial UNED.

Carterette, E. y Friedman, M. (1982). Manual de percepción. Raíces históricas y filosóficas. México: Trillas.

Castells, M. (2001). La Galaxia Internet. Reflexiones sobre Internet, empresa y sociedad. En La Sociedad Red. Vol. 1. Madrid: Alianza Editorial. https://doi.org/10.1007/978-3322-89613-1

Castro, Y. (2007). La educación para el desarrollo humano en un mundo globalizado. Revista tendencia de retos (12), 157-175.

Coll, C. (2008). Psicología de la educación virtual: aprender y enseñar con las tecnologías de la información y la comunicación. Ediciones Morata.

Colle, R. (2002). “Teoría Cognitiva Sistémica de la Comunicación. Santiago de Chile, Ed. San Pablo.

Correa, J. (2005). La integración de plataformas de elearning en la docencia universitaria: enseñanza, aprendizaje e investigación con "Moodle" en la formación inicial del profesorado. Revista Latinoamericana de Tecnología Educativa, 4(1). 37-48.

Del Moral, M., \& Martínez, L. (2012). Didáctica universitaria en la era 2.0: competencias docentes en campus virtuales. RUSC. Universities and Knowledge Society Journal, 9 (1), 36-50. https://doi.org/10.7238/rusc.v9i1.1127

Díaz y Ledesma (2011). eXeLearning: herramienta de autor para una Escuela 2.0. Revista Digital La Gaveta.17, 90-105. Duart, J. \& Sangrá, A. (2000). Aprender en la virtuali dad. Barcelona: Gedisa.Catalunya - España.

Galvis, N. (2017). Exelearning como Estrategia Pedagógica para el Fortalecimiento del Pensamiento Lógico Matemático en Niños de Educación Preescolar. CIE, 2(4), 59-74.

García, F (2005). Estado actual de los sistemas e-learning. En Teoría de la educación: educación y cultura en la sociedad de la información. Universidad de Salamanca, 6(2). Gesa, R. (2012). Combinando la realidad aumentada con las plataformas de e-elearning adaptativas. Revista Venezolana de Información, tecnología y conocimiento, 9 (2), 69-78.

Gilberto, O. (2004). La definición del concepto de percepción en psicología con base en la teoría Gestalt. Revista de Estudios Sociales, (18), 89-96. https://doi.org/10.7440/ res18.2004.08

Gonzáles, E. (2013). Acerca del estado de la cuestión o sobre un pasado reciente en la investigación cualitativa con enfoque hermenéutico. Unipluriversidad, 13(1), 60- 63. Gregori, E., \& Garganté, A. (2005). El uso educativo de las aulas virtuales emergentes en la educación superior. RUSC. Universities and Knowledge Society Journal, 2 (2), 2.

Hernández-Sampieri, R., Fernández, C., \& Baptista, P. 
(2014). Metodología de la Investigación. México: Mc Graw Hill.

Iazza, G. y Pinzón, S. (2005) El E-Learning en la Enseñanza Universitaria: El Centro de Enseñanzas Virtuales de la Universidad de Granada y su Adaptación Al Eees. Centro de Enseñanzas Virtuales de la Universidad de Granada. España

Larrosa, J. (2006). Sobre la experiencia. Aloma. Revista de Psicologia i Ciències de l'Educació, 2006, num. 19, p. 87112 .

López Ortiz, R. H. (2016). Análisis de las leyes de la Gestalt y su aplicación en materiales didácticos para niños de educación inicial II (Doctoral dissertation, Ecuador-PUCESE-Escuela de Diseño Gráfico).

Koffka, K. (1922): "Una introducción a la Gestalt-Theorie”. En La teoría de la Estructura (K. Koffka), Ediciones de la Lectura, Madrid.

Marcelo, D.; Puente, D. y Ballestero, A. (2002). E-learning-teleformación. Diseño, desarrollo y evaluación de la formación a través de Internet. Editorial Gestión 2000. Madrid.

Marrero, O., \& Perez, M. (2014). Competencias investigativas en la educación superior. RES NON VERBA, 55-68.

Martín, Á., \& de la Rosa, C. (2011). Manual práctico de psicoterapia Gestalt. Desclée de Brouwer.

Martínez, M. (2009). Ciencia y arte en la metodología cualitativa. México: Trillas.

Méndez, C. (1999). Metodología. (2a. ed.). Santa Fe de Bogotá: Limpres Ltda.

Naula, M. (2017). Importancia de la motivación en el aprendizaje. Sinergias Educativas, 2(1). https://doi.org/10.31876/s.e.v2i1.20

Pérez, A. (2007). Espacios virtuales en educación. Revista Academia, 6 (12), 2-12.

Pineda, W., Casanova, M. \& Bracho, K., (2020). Objeto virtual de aprendizaje en la Cátedra de Paz para estudiantes de educación básica primaria. Hamut’ay, 7(1), 9-18. https:// doi.org/10.21503/hamu.v7i1.1894

Pupiales, A. (2009). Impacto de las aulas virtuales como mediación pedagógica en las asignaturas presenciales de pregrado del Departamento de Humanidades de la Universidad Militar Nueva Granada. Revista Educación y Desarrollo Social, 3 (2), 79-87.

Quintero, M. (2003). Un enfoque gestáltico en la formación educativa. México, Trillas

Rodríguez, R. \& Vaca, V. (2018). Importancia de las herramientas y entornos de aprendizaje dentro de la plataforma e-learning en las universidades del Ecuador. Edutec. Revista Electrónica De Tecnología Educativa, (65), 68-92.

Ros, I. (2008). Moodle, la plataforma para la enseñanza y organización escolar. Ikastorratza, e- Revista de Didáctica 2. Retrieved from http://www.ehu.es/ikastorratza/2_alea/ moodle.pdf (issn: 1988-5911).

Rosemberg M. (2002). E-learning: Estrategias para transmitir conocimiento en la era digital. Bogotá: McGraw-Hill Interamericana.

Schuster, A.; Puente, M.; Andrada, O., y Maiza, M. (2013).
La Metodología Cualitativa, Herramienta para Investigar los fenómenos que ocurren en el aula. La Investigación Educativa. Revista Electrónica Iberoamericana de Educación en Ciencias y Tecnología, 4(2), 111- 139.

Sierra, R (2001). Técnicas de investigación social. Paraninfo S.A.- Thomson Learning. España.

Taylor \& Bogdam (1986) Introducción a los Métodos Cualitativos de Investigación - la Búsqueda de Significados. Argentina: PAIDOS. ISBN 13: 9789501268379.

Urdan, T. A., \& Weggen, C. C. (2000). Corporate e-learning: Exploring a new frontier. San Francisco, USA: WR Hambrecht.

Vargas, F. F. (2008). Gestalt y aprendizaje. Revista Electrónica” Actualidades Investigativas en Educación", 8(1), 1-12. Vivas, J. (2011). Modelos pedagógicos en educación a distancia. REDHECS, 12, 86-113.

Wertheimer, M. (1912). Estudios experimentales sobre la visión del movimiento. Zeitschrift der Psychologie, 61, 161-265.

Zorrilla, S. y M. Torres (1992). La Tesis, 2a. ed., Ed. McGraw-Hill, México. 